\title{
LEARNING A PARENTAL ROLE DURING THE PROCESS OF REHABILITATION AND FAMILY INTEGRATION, WITHIN PRISON SETTINGS
}

\author{
Ewelina Startek \\ Klaudia Węc \\ Akademia Ignatianum w Krakowie, Poland
}

\begin{abstract}
Family relationships can give people a valuable sense of identity, belonging, security and responsibility. Families are important to us all, but for prisoners, they can make a huge difference to rehabilitation. They can provide emotional support and a home to go to on release. They can also provide financial assistance and help to find work. All of these things can help to reduce the risk of re-offending: Research suggests that having family ties can reduce the likelihood of re-offending by 39 percent. However, not all family relationships are positive and helpful.

Not all imprisoned parents have the opportunity to learn a parenting role before they are sentenced-they may have a negative experience of being parented, themselves. Therefore, prison might offer their first opportunity to learn a parental role and to learn about parental responsibilities. These new skills may enable them to break the cycle of crime, desist from future offending, and may impact on the prevention of intergenerational crime. To ensure that the process of learning parenting skills delivers its full potential, all members of a family should be involved, with adults and children learning together.
\end{abstract}

Keywords: children of imprisoned parents, family, integration, lifelong learning, parenting role.

\section{Introduction}

Going into prison is a difficult experience for offenders and their families. As a result of imprisonment, prisoners lose most of the roles they performed before. The parenting role should not only be continued but should be supported and used as an important tool in rehabilitation process. Prisoners are separated from the world they know and can find it difficult to become part of society again after they have served their time. Prisoners' families also suffer, even though they have not committed a crime. They can face financial and housing difficulties caused by loss of income, they can suffer from anxiety and depression, and they are often ostracised by neighbours and friends. Families have to cope with the practical, financial and emotional consequences (Mills, 2004). Therefore maintaining the relationships between prisoners and their relatives can be a 
Startek \& Węc, 2018. Learning a Parental Role During the Process of Rehabilitation and Family Integration, Within Prison Settings

particularly challenging. Prisoners might serve their sentence a long way from home, so families have to bear the stress and cost of travel. They are faced with rigid visiting hours, are subject to searches, and may be treated with suspicion by prison staff. What is more, the prison may feel intimidating and hostile. Nevertheless family relationships can give people a valuable sense of identity, belonging, security and responsibility. Families are important to us all, but for prisoners, they can make a huge difference in rehabilitation. They can provide emotional support and a home to go to on release.

\section{Maintaining family ties}

The United Kingdom Ministry of Justice's own research shows that for a prisoner who receives visits from a family member the odds of reoffending are 39 $\%$ lower than for those who do not (May et al., 2008). Yet in Polish Prison and Probation System there is an inconsistency of respect for the role families can play in boosting rehabilitation and assisting in resettlement across the prison system. The role of family is not treated in the same way as employment and education. Family work should always be seen and referred to alongside these two rehabilitation enablers. In Poland there are only few non-governmental organizations working with prisoners and their families, usually struggling to get funding and support. This is partly because work to help offenders rehabilitate is a relatively unpopular cause that elicits little public sympathy or political interest - in the field of offenders and their families, the difficulty in attracting support goes further than this. However, if prisons are truly to be places of reform, we cannot ignore the reality that a supportive relationship with at least one family member is indispensable to a prisoner's ability to serve their sentence well and achieve rehabilitation.

Consistently good family work, which brings prisoners face-to-face with their enduring responsibilities to the family, is indispensable to the rehabilitation culture we urgently need to develop in our penal system, and has to be integral to the changes required. Families need to be willing and able to engage with the rehabilitation process, as well as needing to feel being a partner in the process (Lord Farmer review, 2018) .

Maintenance of strong family ties is equally vital for the children of prisoners. Research shows that the outcomes for children of prisoners can be hugely negative. Early studies suggested that parental imprisonment might cause a range of adverse outcomes. Ambiguous loss, disrupted attachment and stigmatisation contribute to a shaken sense of ontological security, all of which together can partly explain the increased risk for intergenerational crime identified in prior research (The COPING Project - Final Report, 2013). Strengthening children's resilience in order to improve their coping capacity is a key path to 
empowering these children and their families, and improving the chances of a healthy, productive adult life.

Gwyneth Boswell's (2002) study of children whose father was imprisoned, found that most children interviewed expressed feelings of sadness or distress and commented on mostly negative changes in their lives since their father's imprisonment. The children were found to entertain a 'mixture of hopes and fears for their continuing and future relationships with their fathers'. Other studies have consistently reported the following psychosocial problems during parental incarceration, including: depression, hyperactivity, aggressive behaviour, withdrawal, regression, clinging behaviour, sleep problems, eating problems, running away, truancy, low academic achievement and delinquency/anti-social behaviour (Farrington \& Murray, 2005). Farrington and Murray's 2005 analysis found that boys separated because of parental imprisonment had higher rates of antisocial-delinquent behaviour, and of mental health problems after statistically controlling for other childhood risk factors in the study (including low child IQ, parental criminality, family poverty, and poor parenting). That means children of imprisoned parents were a 'highly vulnerable group with multiple risk factors for adverse outcomes'. For instance, 71 percent of boys who experienced parental imprisonment during childhood had antisocial personalities at age 32, compared to 19 per cent of boys who did not share this experience (Farrington \& Murray, 2005). Furthermore, the study found that children of imprisoned parents were likely to be 'disproportionately represented in clinical populations'. Most crucially, 'parental imprisonment predicted boys' mental health problems throughout the life-course', and up until age 48, with 36 percent having high levels of anxiety or depression at age 48 compared to 15 percent of boys with no history of parental imprisonment or separation. Compared to their peers, children of prisoners have been found to have three times the risk for mental health problems, anti-social delinquent behavior and other adverse outcomes (Farrington \& Murray, 2009).

Parental imprisonment threatens a child's sense of attachment security. This is linked with Bowlby's attachment theory (Bowlby, 1969), which states that young children require dependable, accepting and intimate contact with their parents for stable emotional development. According to Bowlby, secure attachment bonds promote positive child development and behaviour, whereas insecure attachment can lead to deficits in social and moral functioning in adulthood. The idea that parent child separation is harmful for children may be especially significant for children of prisoners because of the way that separation can often occur.

Although a large number of children are affected by parental imprisonment there is a lack of research into the topic, and the problem appears to be worldwide. The research that has been carried out in several countries into the effects 
Startek \& Węc, 2018. Learning a Parental Role During the Process of Rehabilitation and Family Integration, Within Prison Settings

of parental incarceration on children illustrates that it can be a very traumatic experience for the child of the offender. However it is extremely difficult to estimate the number of children who are affected by parental imprisonment every year. In Poland no data is collected on a national scale. Despite this, last year the Polish Ministry of Justice announced that there are 47,000 children with a parent in prison. The number was given in response to a request asked by a journalist involved in an international champagne "Not my crime, still my sentence" regarding a situation of children of prisoners in Poland. The credibility of this information is somehow questionable (Jaroń, 2017).

According to Children of Prisoners Europe (COPE) a network of non-profit organizations, there are 2.1 million children affected by imprisoned in Europe. This is an umbrella organization, consisting of professionals and academics working to support children separated from a parent in prison with 28 members in 16 countries across Europe. Their aim is to promote and protect the rights of children with imprisoned parents and to ensure that these rights - as enshrined in the UN Convention on the Rights of the Child (UNCRC) and the European Convention on Human Rights, are taken into account. Between 2010 and 2012 the organization led a child-centred project, which investigated the resilience and vulnerability to mental health problems of children of imprisoned parents. It was the first time that a study of its size focused on the resilience and vulnerability of children of imprisoned parents throughout Europe. The study covered four countries: Sweden, Romania, Germany and the UK. COPING research findings are aimed towards implementing European and international public policies in the view of enhancing the welfare of children. Support for children in accessing prisons and participating in prison visits, for example, is highly needed since only non-governmental organisations provide such services. Moreover, these methods vary greatly from one country to another (The COPING Project: Final Report, 2013).

Garmezy (1993) defines resilience as the individual ability to adjust properly, positively or feeling competent despite being at serious risk. Newman and Blackburn (2002) provided a definition for resilience in children. They state that resilient children are more capable at confronting stress, managing change and indecision and recuperate more quickly and thoroughly from disturbing incidents. Children's resilience is closely related to sharing information with them openly and honestly about what has happened and the reasons for their parent's imprisonment, consistent with their age and maturity. Above all, honesty is good for children and helps promote their positive mental health. Children of prisoners are sometimes told nothing or false stories about what happened to the imprisoned parent. Non-disclosure may come from a desire to protect the child, parents may lie pre-trial, assuming they'll be found not guilty and return. However, imprisoned parents may be motivated to protect themselves rather than do what is best for the 
child or the family. Some prisoners think that by keeping the imprisonment secret, they could return to the family and things would be the same as before the sentence. Sometimes one parent wants to tell the truth and the other does not, which adds difficulty. Children find it much harder to deal with the parent's absence if the truth is concealed: it can increase insecurity and erode trust between parents and children. Children may find out the truth from other sources. Disclosure of the imprisonment in an age-appropriate way can help the children adjust to the situation and reduce feelings of anxiety and guilt. Children can be more resilient and adaptable to adversity than adults often recognise. Honest disclosure can help children see the consequences of actions. Even young children were thought by some to benefit from knowing the sequences of events and what would happen when, particularly as children often subconsciously pick up on what is occurring. Parents may need assistance in how to tell their children (The COPING Project - Final Raport, 2013).

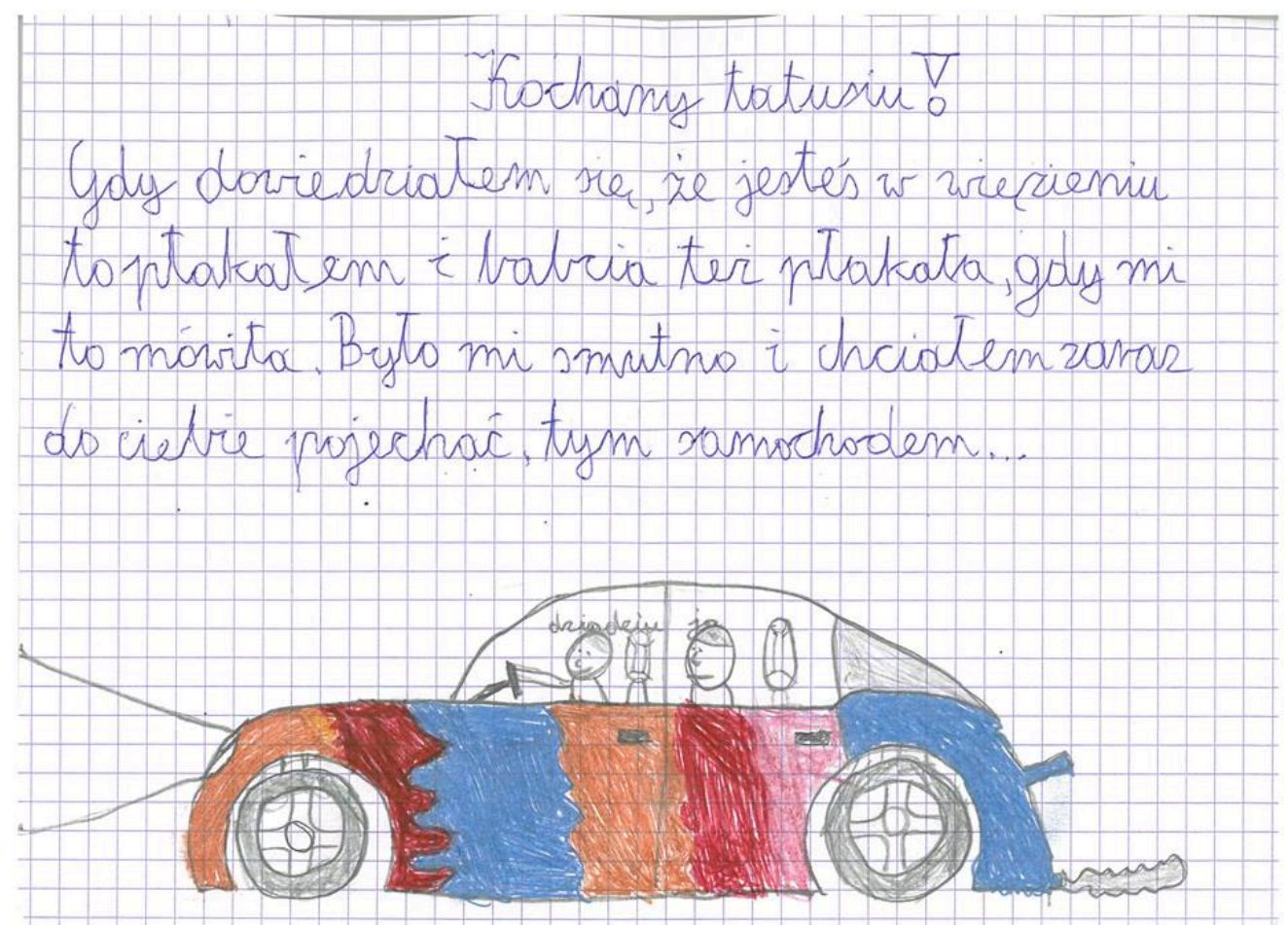

Figure 1. The letter from a child to his dad: "Dear Daddy, when I found out that you are in a prison, I cried, and granny also cried when she was telling me this. I felt sad and wanted to come and visit you, by this car”

COPING research also recognised the potential role of imprisoned parents as active agents in promoting children's welfare (Mahmoudi et al., 2015). Encouraging imprisoned parents to contribute to their children's daily lives can be problematic because they might not appreciate how hard it is for their children 
Startek \& Węc, 2018. Learning a Parental Role During the Process of Rehabilitation and Family Integration, Within Prison Settings

to deal with their imprisonment. They might not realise just how important they are in promoting their child's welfare and they may fail to see how they can possibly carry out from prison their role as a parent. Imprisoned parents need to have their awareness raised about the importance of their role, the difficulties their children may face and the various positive coping strategies that the family can develop. Just as carers need support on the outside, the imprisoned parent should be offered advice and support on parenting from within the prison through the provision of and participation in parenting groups and classes. But it is not just a case of changing perceptions. Imprisoned parents cannot execute their parenting role without continuing quality contact with their child. Therefore a suitable, child - friendly space should be provided for children visiting prisons, with non judgmental approach.

Another aspect which children of imprisoned parents have to face is stigma. Parental imprisonment very often leads to children being labelled as different, as having an undesirable characteristic and being in a category of "them" as opposed to "us" (Eddy \& Poehlmann, 2010). The stigma of having a parent in prison can cause children of prisoners to be labelled and rejected by peers, while children may feel they are different from others and withdraw from social contacts. They do not attract sympathy from others and can be stigmatised by prison staff, school staff and parents of their friends. Fear of stigma can stop children telling others about the situation, which can mean their problems are often hidden.

Although the prison environment is often destructive to family relationships, it can also provide a window of opportunity for change. National and international research indicates parents in prison are often motivated to use this period to reflect on their relationships with their child and to improve their capacity to parent.

Parenting programmes within the Prison System provide a unique opportunity to promote a range of parenting skills to, often to parents unlikely to engage in parenting education in the outside world. It also provides a safe space for prisoners to reflect upon and rethink their role as a parent, it can assist and support them through the process of imprisonment, potential release and resettlement into family life. The opportunity for parents in prison to contribute to a different childhood for their own children may help break the potential cycle of intergenerational crime and increase their own motivation not to re-offend (Purvis, 2011).

Programmes designed for imprisoned parents should differ from other programmes in two significant ways. In addition to focusing on the development of parenting skills, they need to deal with the challenge of parenting within the context of imprisonment and provide parents with the skills and strategies needed for positive engagement with their children, families and communities after release. This means addressing those factors that might threaten successful reintegration. Additional topics critical for this population might include 
identifying and avoiding abusive or negative relationships, staying away from drug and alcohol misuse, dealing with past trauma and life development skills. Many men and women who become imprisoned may also have experienced much childhood adversity, for example, domestic violence, substance abuse and physical or sexual abuse. Many may have lacked positive adult role models during their developmental years and, as the research states, these early experiences will inevitability shape their own parenting style in later life. Hence, there is a real need for incarcerated parents to be offered education and training in effective parenting, given that most lack the knowledge necessary to demonstrate positive parenting (Purvis, 2011). Parenting programmes can be successful in helping parents develop their skills and resources, which, help them to parent more effectively. Components within the programmes can enhance parental knowledge of child development and positive parenting styles, which then can lead to enhanced parenting skills and parental self-esteem (Wilson et al., 2011).

Parenting support should also differ whilst being offered for imprisoned fathers or mothers. Given the distinctive emotional and practical role a mother has in a child's life, the experience of a mother in prison is usually qualitatively different to that of a father in prison. Unlike fathers in prison, whose child is usually living at home with its mother (the prisoner's partner or ex-partner), when the mother is arrested, and she is the primary or sole carer, then the probability of disruption on the children's lives is higher. This not only relates to the change of the carer, but also to the changing of home, friends, school and sometimes separation from siblings (Simmons, 2003). Another consequence is the fact that grandparents as carers (usually grandmothers) may be old and/or ill and with restricted economic resources. These grandmothers have to deal at the same time with the emotional and social problems of having a son or daughter in jail along with supporting children of separated parents (Ann Cunningham, 2001). In addition to this, research also highlights that two in three imprisoned women have mental health problems, at least half report being victims of domestic violence and 37 percent have tried to kill themselves. Nine out of ten women are convicted of non-violent offences, and two-thirds of women in prison are mothers (HMP Report 2005). Inevitably therefore, maintaining relationships between the mother and child is fraught with difficulty and the impact on the child can have far reaching consequences.

In order to meet all the above described individual, very often multiple and complex needs, it is crucial that highly qualified stuff is selected to provide parenting support. Moreover, due to the nature of this work, and the necessity of reaching all members of those families, the imprisoned ones as well as the people on the other side of the wall, it becomes apparent that prison stuff doesn't have the required skills. People supporting families affected by imprisonment have to fulfil the space between the prison and local communities. Another obstacle is the 
Startek \& Węc, 2018. Learning a Parental Role During the Process of Rehabilitation and Family Integration, Within Prison Settings

fact that the roles of a prison officer and a family support worker are based on different values, which are difficult to combine. The first one is mostly about oppression whilst the second has more therapeutic approach. Therefore nongovernmental organizations play such an important role in this process.

In the Małopolskia region, Probacja Association works with families affected by imprisonment, delivering parenting programs, organizing special children's visits as well as running an early intervention service providing individual support for children and young people affected by the imprisonment. In 2017, for the first time in Poland, they joined a pan-European campaign entitled "Not my crime, still my sentence" to raise awareness about the rights and needs of children with an imprisoned parent. The aim of the campaign was exploring new ways to improve children's prison visits, giving children their voice as well as raising the awareness among teachers and social workers, by showing how ordinary children have to deal with unusual life circumstances.

\section{Summary}

The above described research shows the importance of supporting parenting roles in prison. Not only from a rehabilitation point of view, but also as a social responsibility to provide care for vulnerable groups. Children affected by parental imprisonment are in the 'at risk' group in society but their problems are hidden, and their voices are not heard. It is time for society to listen. Children shouldn't be punished for what their parents have done. It is time to think more widely about prison reform, not only for the imprisoned parents, but their children and family members who are also serving a punishing sentence outside the prison gates. Supporting a parenting role is a positive way to contribute to the whole process by strengthening family bonds, developing skills, emphasizing the importance of education. Parenting programs can provide the tools for parents to better understand their children, and consequently to support them in both their social and educational development.

\section{References}

Boswell, G. (2002). Imprisoned Fathers: The children's view. The Howard Journal of Criminal Justice, 41.

Bowlby, J. (1969). Attachment and loss. Vol. 1. Attachment. New York: Basic Books. Penguin Books.

COPING Final Report. Retrieved from http://childrenofprisoners.eu/wp-content/ uploads/2013/12/COPINGFinal.pdf

Cunningham, A. (2001). 'Forgotten Families - the impacts of imprisonment'. Family Matters, 59, 35-38.

Eddy, J. M., \& Poehlmann, J. (2010). Children of Incarcerated Parents: A Handbook for Researchers and Practitioners. The Urban Institute Press.

Garmezy, N. (1993). Vulnerability and resilience. In D. C. Funder, R. D. Parke, C. TomlinsonKeesey \& K. Widaman (Eds.), Studying lives through times: approaches to personality and development. Washington, DC: American Psychology Association. 
HM Chief Inspector of Prisons for England and Wales Annual Report 2005. Retrieved from https://www.gov.uk/government/publications/annual-report-of-hm-chief-inspector-ofprisons-2004-to-2005

Jaroń, D. (2017). Nie moja wina, ale moja kara. Retrieved from http://fakty.interia.pl/ autor/dariusz-jaron/news-nie-moja-wina-ale-moja-kara,nId,2381600

May, C., Sharma, N., \& Stewart, D. (2008). Prisoners who took part in the Resettlement Surveys 2001, 2003 and 2004. London: Ministry of Justice Research.

Mills, A. (2005). Great Expectations? A Review of the Role of Prisoners' Families in England and Wales'. Selected Papers from the 2004 British Criminology Conference, Volume 7, University of Portsmouth.

Mahmoudi, S., Leviner, P., Kaldal, A., \& Lainpelto, K. (2015). Child-friendly Justice: A Quarter of a Century of the UN Convention on the Rights of the Child. Leiden. Boston. Brill Nijhoff.

Murray, J., \& Farrington, D. P. (2005). Parental Imprisonment: Effects on Boys' Antisocial Behavior and Delinquency Through the Life-Course. Journal of Child Psychology and Psychiatry, 46 (12).

Murray, J., Farrington, D. P., Ivana Sekol, \& Rikke, F. Olsen (2009). Effects of Parental Imprisonment on Child Antisocial Behaviour and Mental Health: A Systematic Review. Campbell Systematic Reviews, 4.

Newman, T., \& Blackburn, S. (2002). Transitions in the lives of children and young people: resilience factors. Report for Scottish executive education and young people research unit. Retrieved from http://www.gov.scot/resource/doc/46997/0024004.pdf

Lord Farmer review (2018). The Importance of Strengthening Prisoners' Family Ties to Prevent Reoffending and Reduce Intergenerational Crime. Retrieved from https://www.gov.uk/ government/uploads/system/uploads/attachment_data/file/642244/farmer-reviewreport.pdf

Purvis, M. (2011). Parental incarceration and parenting programs in prison: a review paper. Psychiatry, Psychology and Law.

Simmons, C. W. (2003). California law and the children of prisoners. California Research Bureau, California State Library. In Harris, Y. R., Graham, J. A. (2010). Children of Incarcerated Parents: Theoretical Developmental and Clinical Issues. Springer Publishing Company.

The United Nations Convention on the Rights of the Child. Retrieved from https://www.unicef.org.uk/what-we-do/un-convention-child-rights/

Wilson, K., Hahn, L., Gonzalez, P., Henry, K., \& Cerbana, C. (2011). An evaluation of partners in parenting: a parent education curriculum implemented by county extension agents in Colorado. Journal of Extension. 